\title{
Spinous Process
}

National Cancer Institute

\section{Source}

National Cancer Institute. Spinous Process. NCI Thesaurus. Code C116112.

A bony projection arising from the posterior vertebral arch that serves for the attachment of muscles and ligaments. 